\title{
Crocin alleviates lipopolysaccharide-induced acute respiratory distress syndrome by protecting against glycocalyx damage and suppressing inflammatory signaling pathways
}

\author{
Dong Zhang ${ }^{1} \cdot$ Bo-yang $\mathrm{Qi}^{1} \cdot$ Wei- wei Zhu ${ }^{1} \cdot$ Xiao Huang $^{1} \cdot$ Xiao-zhi Wang ${ }^{1}$
}

Received: 6 August 2019 / Revised: 25 December 2019 / Accepted: 31 December 2019 / Published online: 10 January 2020

(c) Springer Nature Switzerland AG 2020

\begin{abstract}
Objective To explore the mechanisms of crocin against glycocalyx damage and inflammatory injury in lipopolysaccharide (LPS)-induced acute respiratory distress syndrome (ARDS) mice and LPS-stimulated human umbilical vein endothelial cells (HUVECs).

Methods Mice were randomly divided into control, LPS, and crocin + LPS (15, 30, and $60 \mathrm{mg} / \mathrm{kg}$ ) groups. HUVECs were separated into eight groups: control, crocin, matrix metalloproteinase 9 inhibitor (MMP-9 inhib), cathepsin L inhibitor (CTL inhib), LPS, MMP-9 inhib + LPS, CTL inhib + LPS, and crocin + LPS. The potential cytotoxic effect of crocin on HUVECs was mainly evaluated through methylthiazolyldiphenyl-tetrazolium bromide assay. Histological changes were assessed via hemotoxylin and eosin staining. Lung capillary permeability was detected on the basis of wet-dry ratio and through fluorescein isothiocyanate-albumin assay. Then, protein levels were detected through Western blot analysis, immunohistochemical staining, and immunofluorescence.

Results This study showed that crocin can improve the pulmonary vascular permeability in mice with LPS-induced ARDS and inhibit the inflammatory signaling pathways of high mobility group box, nuclear factor $\mathrm{\kappa B}$, and mitogen-activated protein kinase in vivo and in vitro. Crocin also protected against the degradation of endothelial glycocalyx heparan sulfate and syndecan-4 by inhibiting the expressions of CTL, heparanase, and MMP-9 in vivo and in vitro. Overall, this study revealed the protective effects of crocin on LPS-induced ARDS and elaborated their underlying mechanism.

Conclusion Crocin alleviated LPS-induced ARDS by protecting against glycocalyx damage and suppressing inflammatory signaling pathways.
\end{abstract}

Keywords Crocin $\cdot$ Inflammatory responses $\cdot$ Glycocalyx damage $\cdot$ LPS $\cdot$ ARDS

\section{Introduction}

Acute respiratory distress syndrome (ARDS) is a wellknown disease with high morbidity and mortality. The main features of ARDS are lung endothelial cell injury, severe inflammatory responses, neutrophil adhesion or infiltration,

\section{Responsible Editor: John Di Battista.}

Dong Zhang and Bo-yang Qi contributed equally to this study.

Xiao-zhi Wang

hxicuwxz@163.com

1 Department of Respirator Medicine and Intensive Care Unit, Affiliated Hospital of Binzhou Medical University, Binzhou 256603, Shandong, China and interstitial edema [1]. At present, ARDS pathogenesis is complicated with LPS-mediated sepsis being a common etiology [2].

Endothelial glycocalyx and inflammatory responses are crucial for the pathogenesis of ARDS. The endothelial glycocalyx, a layer of negatively charged gel-like substance, exists on surfaces of pulmonary vascular endothelial cells. Heparan sulfate (HS) and syndecan-4 (SDC-4) are highly abundant in the glycocalyx [3,4]. The endothelial glycocalyx plays an important role in albumin exudation formation, leukocyte adhesion, and anticoagulation [5-8]. However, the glycocalyx undergoes dynamic changes and is susceptible to various factors. Enzymes are a key factor in glycocalyx degradation. Glasner et al. [9] reported that heparanase (HPA) and cathepsin L were connected with HS shedding in dengue virus non-structural protein 1-induced endothelial 
hyperpermeability. Reine et al. [10] reported that matrix metalloproteinase 9 (MMP-9) was related to the degradation and shedding of SDC-4 in glomerular endothelial cells.

Excessive inflammation plays an important role in the development of ARDS. Neutrophils are among the first inflammatory responders against acute bacterial inflammation. However, sepsis can induce changes in the deformation ability of neutrophils in pulmonary capillary and their retention on the surfaces of endothelial cells, thereby increasing the capillary permeability of alveoli and inducing and promoting the production of inflammatory cytokines [11]. High mobility group box 1 (HMGB-1), nuclear factor $\kappa B$ (NF-kB), and mitogen-activated protein kinase (MAPK) signaling pathways are important and common inflammatory signaling pathways in lung injury [12-14]. Activation of the inflammatory signaling pathways promotes the production and release of high levels of pro- and anti-inflammatory factors. Imbalance in the pro- and anti-inflammatory internal environment of the body leads to damage to vascular cells, cell dysfunction, adhesion or infiltration of inflammatory cells, and hemodynamic changes.

Crocin is an ester glycoside extracted from saffron. As one of the main active constituents of saffron, crocin has many pharmacological effects, such as anti-oxidation [15], anti-arteriosclerosis [16], anti-apoptosis [17], and anti-inflammatory [18]. However, no studies have reported the effects of crocin on endothelial glycocalyx, HMGB-1, $\mathrm{NF}-\kappa \mathrm{B}$, and MAPK signaling pathways in LPS-induced ARDS mice and LPS-stimulated HUVECs.

This study conducted an in-depth analysis of the protective effects and mechanisms of crocin on LPS-induced ARDS. Overall, the results of this study may provide a pharmacological basis for crocin in ARDS treatment.

\section{Materials and methods}

\section{Reagents}

Crocin (purity assay of $\geq 98 \%$ ) was purchased from Shanghai Yuanye Biological Technology Co., Ltd. Methylthiazolyldiphenyl-tetrazolium bromide (MTT), LPS, 4,6-diamidino2-phenylindole dihydrochloride (DAPI), fluorescein isothiocyanate (FITC)-albumin, and dimethyl-sulfoxide (DMSO) were obtained from Sigma-Aldrich. Rabbit monoclonal antibody to HMGB1 (ab79823), NF-кB p65 (ab32536), I $\mathrm{B} \alpha(\mathrm{ab} 32518), \mathrm{p}-\mathrm{I} \kappa \mathrm{B} \alpha(\mathrm{ab} 133462)$, JNK (ab112501), ERK (ab184699), p38 (ab170099), p-ERK (ab201015), p-JNK (ab4821), p-p38 (ab47363), LaminB1 (ab133741), MMP-9 (ab38898), HPA (ab85543), SDC-4 (ab24511), Ly6g (ab25377), $\beta$-actin (ab8224), GAPDH (ab181602), MMP-9 inhibitor (MMP-9 inhib, ab142180), and FITC (ab25539) were acquired from Abcam Trading Company Ltd. Mouse polyclonal antibody to cathepsin L (CTL) was purchased from Santa Cruz Biotechnology. Mouse polyclonal antibody to HS was purchased from AMS Biotechnology (Switzerland, MA). Thrombomodulin/BDCA-3 was obtained from R\&D Systems (USA). HRP-conjugated goat anti-rabbit IgG, goat anti-rabbit IgG/Alexa Fluor 594, and rabbit anti-goat IgG/Alexa Fluor were purchased from Beijing Biosynthesis Biotechnology Co., Ltd. Cathepsin L inhibitor (CTL inhib, CAS 167498-29-5) was obtained from Santa Cruz Biotechnology.

\section{Cell culture and treatment}

HUVECs were purchased from Cell Line Bank (Shanghai, China). HUVECs were cultured in complete culture medium (AllCells, Shanghai, China) in an incubator with a humidified atmosphere of $95 \%$ air and $5 \% \mathrm{CO}_{2}$ at $37{ }^{\circ} \mathrm{C}$. Cells at 80-90\% confluence were used for all assays.

MTT assay, also known as MTT colorimetric assay, is a method used to detect cell survival and growth. The potential cytotoxic effect of crocin on HUVECs was mainly evaluated by MTT assay. The concentration range of $0-40 \mu \mathrm{mol} / \mathrm{L}$ was randomly selected. As shown in Fig. 4f, the concentration of $20-40 \mu \mathrm{mol} / \mathrm{L}$ crocin showed slight cytotoxicity to the HUVECs. Thus, $20 \mu \mathrm{mol} / \mathrm{L}$ was selected as the pretreatment concentration of HUVECs.

For pretreatment, HUVECs were separated into eight groups: control, crocin, MMP-9 inhibitor (MMP-9 inhib), CTL inhibitor (CTL inhib), LPS, MMP-9 inhib + LPS, CTL inhib + LPS, and crocin + LPS. In the control group, HUVECs were only cultured in the complete culture medium without intervention. In the crocin group, HUVECs were cultured in the complete culture medium with $20 \mu \mathrm{M}$ concentration of crocin. In the MMP-9 inhib group, HUVECs were cultured in the complete culture medium with $5 \mu \mathrm{M}$ concentration of MMP-9 inhibitor. In the CTL inhib group, HUVECs were cultured in the complete culture medium with $10 \mu \mathrm{M}$ concentration of CTL inhibitor. In the LPS group, HUVECs were cultured in the complete culture medium with $1 \mu \mathrm{g} / \mathrm{mL}$ concentration of LPS. In the MMP-9 inhib + LPS group, HUVECs were pretreated with $5 \mu \mathrm{M}$ concentration of MMP-9 inhibitor for $1 \mathrm{~h}$ before the LPS $(1 \mu \mathrm{g} / \mathrm{mL})$ stimulation for $6 \mathrm{~h}$. In the CTL inhib + LPS group, HUVECs were pretreated with $10 \mu \mathrm{M}$ concentration of CTL inhibitor for $1 \mathrm{~h}$ before the LPS $(1 \mu \mathrm{g} / \mathrm{mL})$ stimulation for $6 \mathrm{~h}$. In the crocin + LPS group, HUVECs were pretreated with $20 \mu \mathrm{M}$ concentration of crocin for $1 \mathrm{~h}$ before the LPS $(1 \mu \mathrm{g} / \mathrm{mL})$ stimulation for $6 \mathrm{~h}$.

\section{Animals and grouping}

Male mice (C57BL/6, 8-9 weeks old, weighing 18-20 g) were purchased from Jinan Animal Feed Center (Shandong, 
China). All mice were housed in plastic cages with $21 \pm 4{ }^{\circ} \mathrm{C}$ and supplied with clean food and purified water. The use of mice accorded with the National Institute of Health Guide for the Care and Use of Laboratory Animals. The experimental mice were assorted into control, LPS, and crocin + LPS $(15,30$, and $60 \mathrm{mg} / \mathrm{kg})$ groups. The doses and administration form of crocin were derived from the pre-experiments and previous reports $[19,20]$. The LPS group mice were injected intraperitoneally with the LPS $(20 \mathrm{mg} / \mathrm{kg})$ for $6 \mathrm{~h}$ to induce ARDS [21]. For the crocin + LPS groups, crocin at 15, 30, or $60 \mathrm{mg} / \mathrm{kg}$ was administered intraperitoneally for 7 days prior to intraperitoneal injection of the LPS for $6 \mathrm{~h}$. At the same time, the control group mice were treated intraperitoneally with the same volume of normal saline. After anesthetizing with $4 \%$ chloral hydrate, lungs were collected and used for experiments.

\section{Cell viability assay}

To assess the effect of crocin on the HUVEC viability, HUVECs were cultured and treated with different concentrations $(0-40 \mu \mathrm{mol} / \mathrm{L}, 100 \mu \mathrm{L} / \mathrm{well})$ of crocin for $24 \mathrm{~h}$ and followed by LPS stimulation $(1 \mu \mathrm{g} / \mathrm{mL}, 100 \mu \mathrm{L} /$ well $)$. After $18 \mathrm{~h}$, the MTT $(20 \mu \mathrm{L}, 5 \mathrm{mg} / \mathrm{mL})$ was added and incubated for $4 \mathrm{~h}$. Supernatant was removed, and the formation of formazan was resolved with $150 \mu \mathrm{L} /$ well of DMSO. Optical density was measured at $570 \mathrm{~nm}$ on a micro-plate reader.

\section{Histopathology and pathological injury score}

Intraperitoneal injection of $4 \%$ chloral hydrate was conducted to anesthetize mice. Mouse lungs were taken out and immersed in $4 \%$ paraformaldehyde for 5 days. These portions were processed and embedded in paraffin. The lung sections ( $5 \mu \mathrm{m}$ thickness) were used for hematoxylin and eosin (HE) staining. The lung injury score criteria were in accordance with the method described by Aeffner et al. [22]. The characteristics of lung injury were alveolar congestion, hemorrhage, infiltration, aggregation of neutrophils in the airspace or vessel wall, and thickness of the alveolar wall.

\section{Immunohistochemical analysis}

The lung paraffin sections ( $5 \mu \mathrm{m}$ thickness) were treated via acetone-benzol dewaxing. Then, the lung sections were placed in a microwave box with a certain $\mathrm{pH} 6.0$ citrate buffer for the antigen retrieval. After the antigen retrieval, lung sections were washed with PBS and incubated with 3\% $\mathrm{H}_{2} \mathrm{O}_{2}$ at room temperature for 10 min to block the activity of endogenous peroxidase. The lung sections were washed again with PBS and incubated with anti-Ly6g antibody at room temperature for $12 \mathrm{~h}$. Then, the lung sections were incubated with secondary antibody and the DAB solutions and hematoxylin. Immunohistochemical images were observed and photographed with a microscope (Olympus BX53, Japan).

\section{Lung wet-dry weight ratio}

Wet-dry (W-D) ratio was used as an indicator of lung tissue edema [23]. Intraperitoneal injection of $4 \%$ chloral hydrate was used to anesthetize mice; lungs were removed, washed, blotted dry, weighed to obtain the wet weight, and subsequently placed in an oven at $60^{\circ} \mathrm{C}$ for 5 days to gain the dry weight.

\section{Detection of lung capillary permeability}

FITC-albumin osmosis analysis is a common method for measuring lung capillary permeability [24]. Mice were injected intraperitoneally with LPS for $6 \mathrm{~h}$, followed by tail vein injection of FITC-albumin $(20 \mathrm{mg} / \mathrm{mL})$. After $1 \mathrm{~h}$ of the FITC-albumin blood circulation, intraperitoneal injection of $4 \%$ chloral hydrate was used to anesthetize mice. The lungs were removed and immersed in $4 \%$ paraformaldehyde for 5 days. These portions were processed and embedded in paraffin and used for FITC-albumin osmosis analysis. After the lung sections had undergone retrieval antigen and purity antigen, the samples were incubated overnight with anti-BDCA-3 and anti-FITC antibodies. The lung sections were washed with PBS (5 min/each time) and incubated with fluorescent secondary antibodies for $30 \mathrm{~min}$. After the DAPI staining, the lung sections were observed immediately under a fluorescent microscope (Olympus, Japan). Finally, relative quantification of immunofluorescence was conducted by using ImageJ.

\section{Immunofluorescence analysis}

To detect the contents of HS, SDC-4, and CTL in HUVECs, we seeded cells on coverslips in 24-well plates. After different pretreatments and treatments, the cells were fixed with $4 \%$ paraformaldehyde and permeabilized with $0.5 \%$ Triton $\mathrm{X}-100$. Subsequently, the coverslips were incubated in serum blocking solution and then incubated with HS, SDC-4, and CTL antibodies to overnight at $4{ }^{\circ} \mathrm{C}$. Primary antibody binding was detected by using FITC-conjugated secondary antibodies. The cell nuclei were stained with DAPI. Finally, images were obtained by using a fluorescence microscope (Olympus BX53, Japan).

To detect the levels of HS, SDC-4, and CTL in lungs, we deparaffinized, dehydrated, and treated for antigen retrieval in the 5- $\mu \mathrm{m}$ lung sections, and then, we permeabilized them with $0.5 \%$ Triton $\mathrm{X}-100$. The sections were washed with PBS and incubated with serum blocking solution and then treated with HS, SDC-4, and CTL antibodies overnight at 


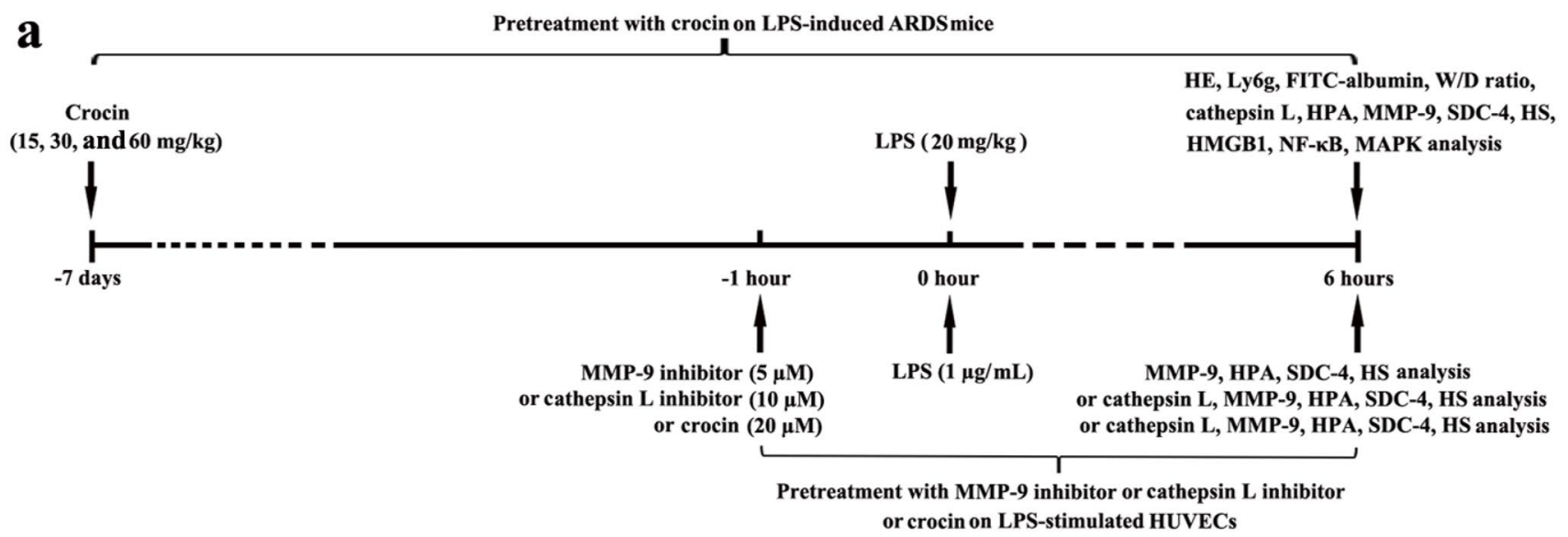

b
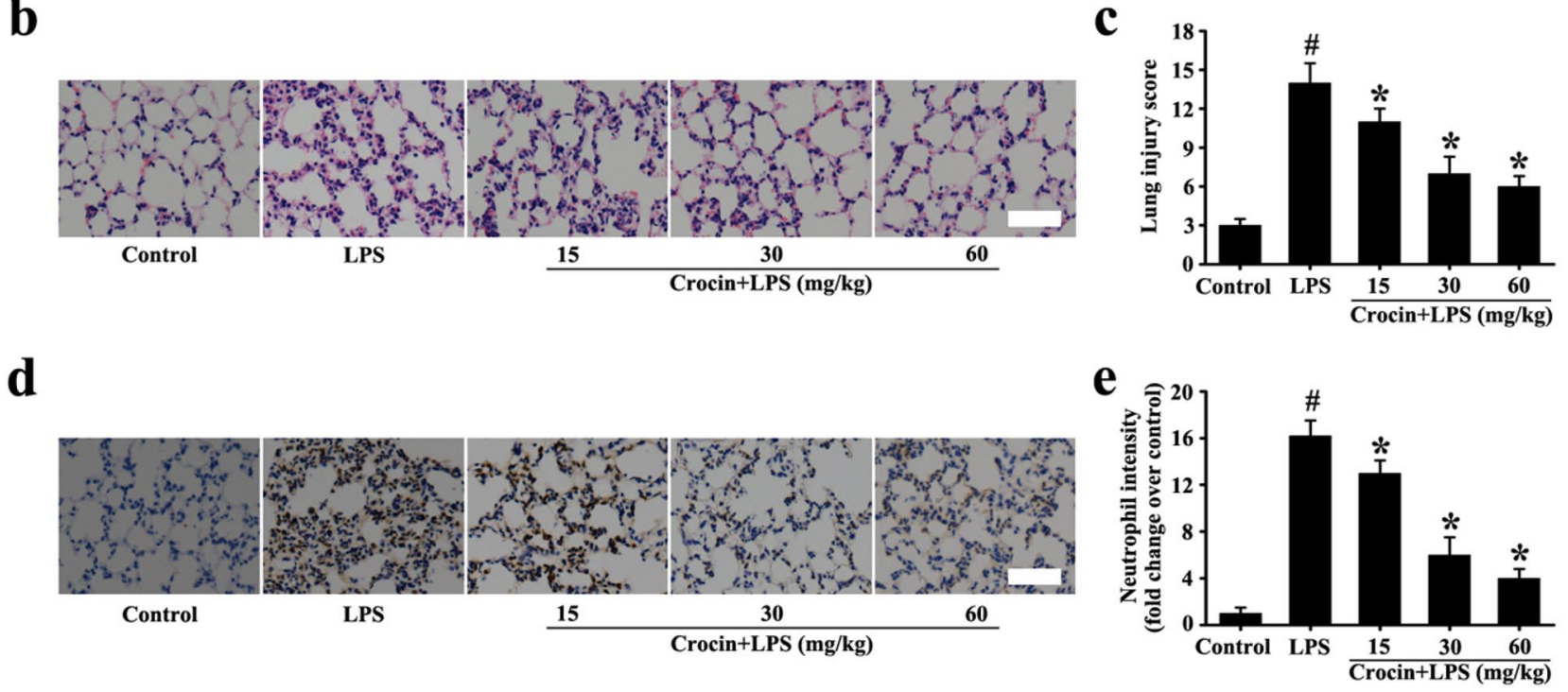

Fig. 1 Experimental schedule of this study and effect of crocin on histopathologic and neutrophil changes in LPS-induced ARDS mice (a). Histological evaluation of lung was conducted by HE staining (b, magnification $\times 200$, scale bar $50 \mu \mathrm{m}$ ). Neutrophil intensity of lung was conducted by immunohistochemical analysis (a, magnification

$4{ }^{\circ} \mathrm{C}$. Thereafter, the sections were washed with PBS and FITC-conjugated secondary antibodies were incubated for $30 \mathrm{~min}$ at room temperature. Lastly, cell nuclei were stained with DAPI. Images were obtained by using a fluorescence microscope (Olympus BX53, Japan).

\section{Western blot analysis}

Intraperitoneal injection of $4 \%$ chloral hydrate was used to anesthetize mice, whose lungs were removed and frozen in liquid nitrogen. The extraction of nuclear and cytoplasmic protein was performed with a protein extraction kit (Beyotime, China), and its concentration was determined by the BCA protein assay kit (Beyotime, China). Equal amounts $\times 200$, scale bar $50 \mu \mathrm{m}$ ). $\mathbf{c}$ Lung injury score of b. e Neutrophil intensity analysis of $\mathbf{d}$. All data are presented as means \pm SD of three independent experiments. ${ }^{\#} p<0.05$ vs. control group, ${ }^{*} p<0.05$ vs. LPS group

of protein were loaded into each well and separated by $10 \%$ sodium dodecyl sulfate-polyacrylamide gel electrophoresis (SDS-PAGE) and transferred to polyvinylidene fluoride (PVDF) membranes. The PVDF membranes were washed by tris-buffered saline with tween 20 (TBST) and incubated with $7 \%$ nonfat milk for $4 \mathrm{~h}$. The PVDF membranes were incubated with primary antibodies (HMGB1, NF- $\mathrm{BB}$ p65, I $\mathrm{B} \alpha, \mathrm{p}-\mathrm{I} \kappa \mathrm{B} \alpha, \mathrm{p} 38, \mathrm{p}-\mathrm{p} 38, \mathrm{JNK}, \mathrm{p}-\mathrm{JNK}, \mathrm{ERK}, \mathrm{p}-\mathrm{ERK}$, LaminB1, MMP-9, HPA, $\beta$-actin, and GAPDH) overnight. The PVDF membranes were washed again with TBST and incubated with HRP-conjugated goat anti-rabbit IgG at 37 ${ }^{\circ} \mathrm{C}$ for $2 \mathrm{~h}$. The protein band at the PVDF membranes was visualized by the chemical exposure solution. 

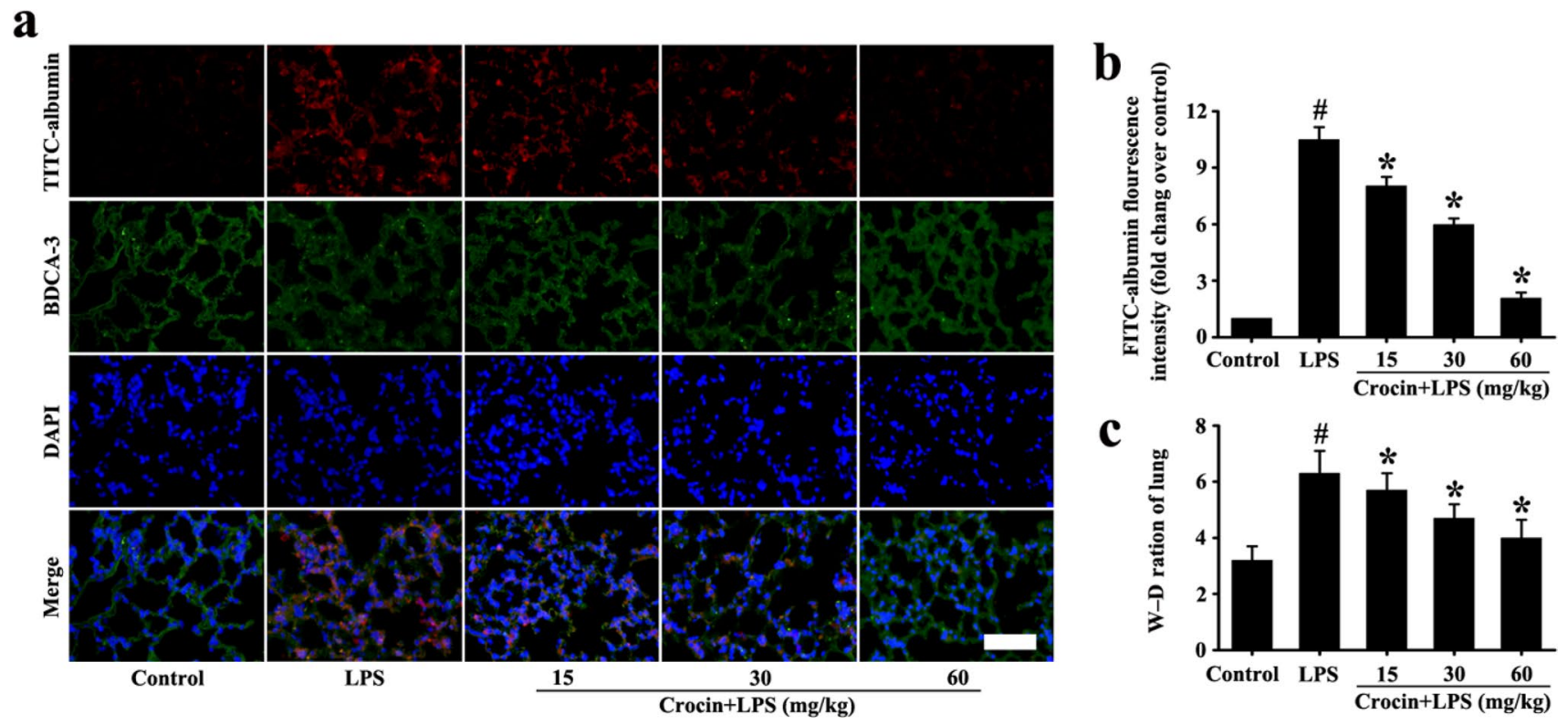

Fig. 2 Effect of crocin on lung permeability in LPS-induced ARDS mice. Following the process shown in Fig. 1a, lung permeability was determined by FITC-albumin osmosis analysis (a, magnification $\times 200$, scale bar $50 \mu \mathrm{m})$ and lung $\mathrm{W}-\mathrm{D}$ ratio $(\mathbf{c})$. b Fluorescence

\section{Statistical analysis}

All data are presented as the mean \pm standard deviation (SD). The differences between groups were analyzed using Student's $t$ test and one-way ANOVA followed by the SNK test. $p<0.05$ was considered to indicate statistical significance. All statistical analyses were performed using SPSS 17.0 (IBM Corp.).

\section{Results}

\section{Effects of crocin on histopathologic changes in LPS-induced ARDS mice}

As shown in Fig. 1b-e, the lung tissues of the control group had complete alveolar structure and almost no neutrophil infiltration. However, the lung tissues of the LPS group showed pulmonary congestion and edema, obvious infiltration of neutrophil cells, and alveolar collapse (Fig. 1b-e). Compared with the LPS group, lung structural damage and neutrophil infiltration significantly decreased with increased pretreatment concentration of crocin in crocin + LPS groups (Fig. 1b-e). These data indicated that pretreatment with crocin can significantly decrease lung injury in LPS-induced ARDS mice. intensity analysis of a. All data are presented as means \pm SD of three independent experiments. ${ }^{\#} p<0.05$ vs. control group, ${ }^{*} p<0.05$ vs. LPS group

\section{Effects of crocin on lung permeability in LPS-induced ARDS mice}

Vascular permeability increase is an important pathological change in ARDS. To study the effect of crocin on vascular permeability in LPS-induced ARDS mice, lung W-D ratio and FITC-albumins were detected. The lung W-D ratio in the LPS group was significantly higher than that of the control group (Fig. 2c). However, pretreatment with crocin significantly reduced the $\mathrm{W}-\mathrm{D}$ ratio (Fig. 2c). The detection of FITC-albumin further indicated that vascular permeability in the LPS group was significantly higher than that in the control group, and pretreatment with crocin significantly reduced albumin permeability (Fig. 2a, b). Therefore, pretreatment with crocin can improve pulmonary vascular permeability in LPS-induced ARDS mice.

\section{Effects of crocin on glycocalyx damage in LPS-induced ARDS mice and LPS-stimulated HUVECs}

The results in vivo showed that SDC-4 and HS were significantly abscised after LPS stimulation compared with the control group (Fig. 3a-d). In pretreatment with crocin groups, SDC-4 and HS abscission were significantly decreased (Fig. 3a-d).

The results in vitro showed that HS and SDC-4 had no significant difference among the control, crocin, MMP-9 


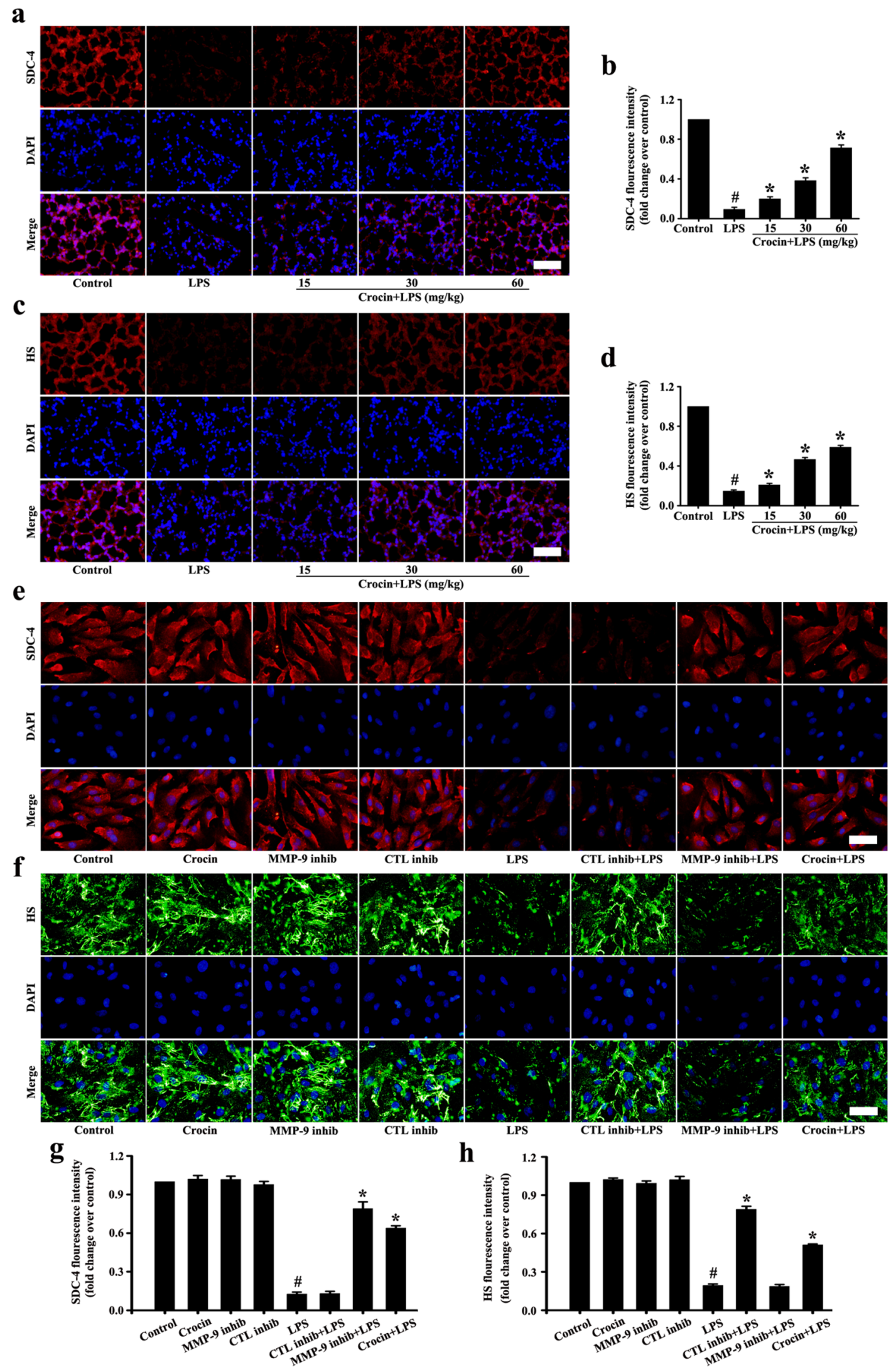


4 Fig. 3 Effects of crocin on SDC-4 and HS in LPS-induced ARDS mice and LPS-stimulated HUVECs. Following the process shown in Fig. 1a, immunofluorescence images of SDC-4 in mice (a) and HUVECs (e) (magnification $\times 200$, scale bar $50 \mu \mathrm{m}$ ). g, b Fluorescence intensity analysis of $\mathbf{e}, \mathbf{a}$, respectively. Immunofluorescence images of HS in mice (c) and HUVECs (f) (magnification $\times 200$, scale bar $50 \mu \mathrm{m})$. h, d Fluorescence intensity analysis of $\mathbf{f}$, $\mathbf{c}$, respectively. All data are presented as means $\pm \mathrm{SD}$ of three independent experiments. ${ }^{*} p<0.05$ vs. control group, ${ }^{*} p<0.05$ vs. LPS group

inhibitor, and CTL inhibitor groups (Fig. 3e-h). After LPS treatment, HS and SDC-4 showed significant shedding in vitro (Fig. 3e-h). Pretreatment with MMP-9 inhibitor significantly reduced the shedding of SDC-4 but had no effect on the shedding of HS (Fig. 3e-h). Pretreatment with CTL inhibitor significantly reduced the shedding of HS but had no effect on the shedding of SDC-4 (Fig. 3e-h). However, HS and SDC-4 shedding with pretreatment crocin were significantly reduced (Fig. 3e-h).

The preceding results indicated that crocin protected HS by inhibiting CTL and HPA and protected SDC-4 by inhibiting MMP-9.

\section{Effects of crocin on CTL and HPA expression in LPS-induced ARDS mice and LPS-stimulated HUVECS}

The in vivo results showed that CTL and HPA were significantly expressed after LPS stimulation compared with the control group (Fig. 4a-d). However, pretreatment with crocin, the expressions of CTL and HPA by LPS stimulation were significantly inhibited (Fig. 4a-d).

The results of CTL and HPA in vitro showed no significant difference among the control, crocin, and MMP-9 inhibitor groups (Fig. 4e, g-i). However, the expression of CTL and HPA was inhibited in the CTL inhibitor group (Fig. 4e, g-i). The expressions of CTL and HPA induced by LPS were significantly inhibited in pretreatment with the CTL inhibitor group (Fig. 4e, g-i). After LPS stimulation, pretreatment with the MMP-9 inhibitor had no significant inhibition on the expressions of CTL and HPA. However, pretreatment with CTL inhibitor significantly inhibited the expressions of CTL and HPA by LPS stimulation (Fig. 4e, g-i).

The preceding results indicated that crocin might inhibit the expression of HPA by inhibiting the upstream protein of CTL in LPS-induced ARDS mice and LPS-stimulated HUVECs.

\section{Effects of crocin on MMP-9 expression in LPS-induced ARDS mice and LPS-stimulated HUVECs}

The results in vivo showed that the expression of MMP-9 by LPS stimulation was significantly increased compared with that of the control group (Fig. 4c, d). However, pretreatment with crocin significantly inhibited LPS stimulation MMP-9 expression compared with LPS treatment (Fig. 4c, d).

MMP-9 expression in vitro showed no significant difference among the control, crocin, and CTL inhibitor groups (Fig. 4h, i). However, MMP-9 expression was suppressed in the MMP-9 inhibitor group (Fig. 4h, i). Compared with CTL inhibitor treatment, the pretreatment with MMP-9 inhibitor significantly inhibited LPS-stimulated MMP-9 expression (Fig. 4h, i).

The preceding results indicated that crocin might protect against SDC-4 shedding by inhibiting LPS-stimulated MMP-9 expression.

\section{Effects of crocin on MAPK inflammatory pathway in LPS-induced ARDS mice and LPS-stimulated HUVECs}

MAPK signaling pathway plays an important role in regulating the inflammatory response of lung injury. In this study, animal results showed that LPS stimulation significantly enhanced the phosphorylation of p38, ERK, and JNK in lungs compared with the control group (Fig. 5a, c). Pretreatment with crocin inhibited the phosphorylation of p38, ERK, and JNK, and the effect was more obvious with increased drug concentration (Fig. 5a, c).

Similarly, cell results showed that only crocin had no effect on the MAPK signaling pathway compared with the control group. However, the significant phosphorylation of p38, ERK, and JNK was observed after LPS stimulation (Fig. 5b, d). Pretreatment with crocin inhibited the phosphorylation of p38, ERK, and JNK (Fig. 5b, d).

These results suggested that crocin can inhibit the activation of MAPK pathway in LPS-induced ARDS mice and LPS-stimulated HUVECs.

\section{Effects of crocin on HMGB1 and NF-KB inflammatory pathway in LPS-induced ARDS mice and LPS-stimulated HUVECs}

The HMGB1 and NF- $\mathrm{KB}$ signaling pathway also regulate lung injury of the inflammatory process. Results in lungs showed that LPS stimulation significantly enhanced $\mathrm{I} \kappa \mathrm{B} \alpha$ phosphorylation, NF- $\kappa$ B p65 nuclear transfer, and HMGB1 cytoplasmic transfer compared with that of the control group (Fig. 6a, c). Pretreatment with crocin can inhibit $\mathrm{I} \kappa \mathrm{B} \alpha$ phosphorylation, $\mathrm{NF}-\kappa \mathrm{B}$ p65 nuclear transfer, and HMGB 1 cytoplasmic transfer compared with that of the LPS group (Fig. 6a, c). The inhibitory effect was more obvious with increased drug concentration (Fig. 6a, c). 
a

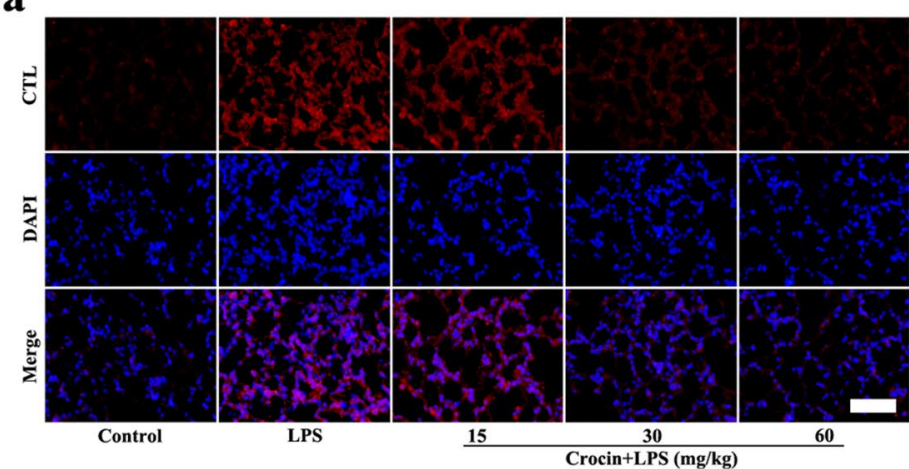

b

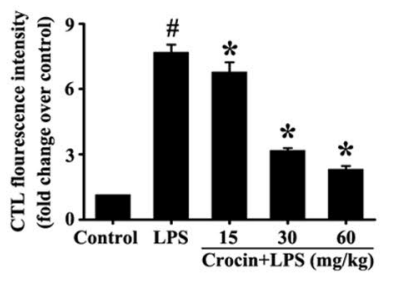

c
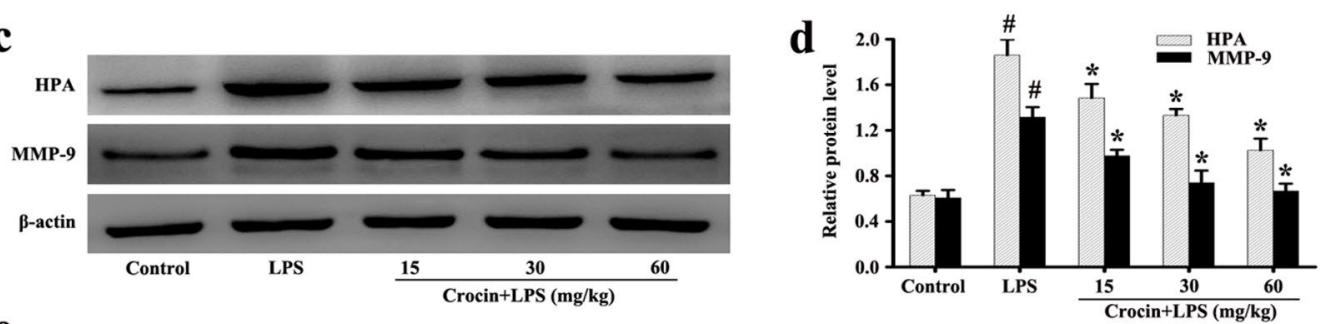

e
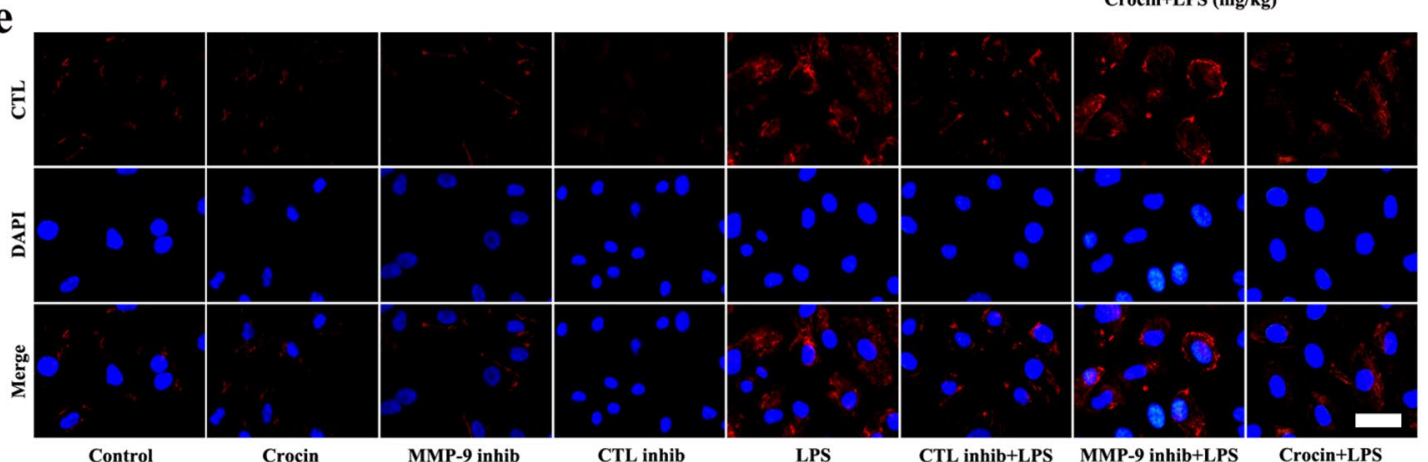

$$
\text { f }
$$

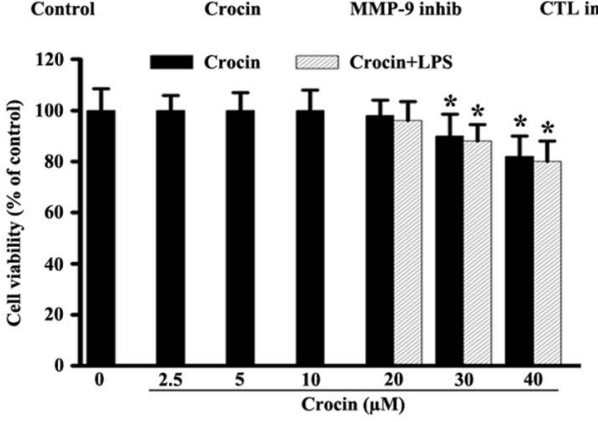

h

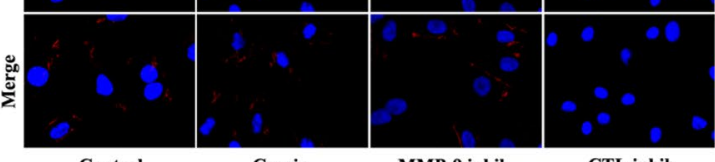

$g^{\mathrm{L}}$
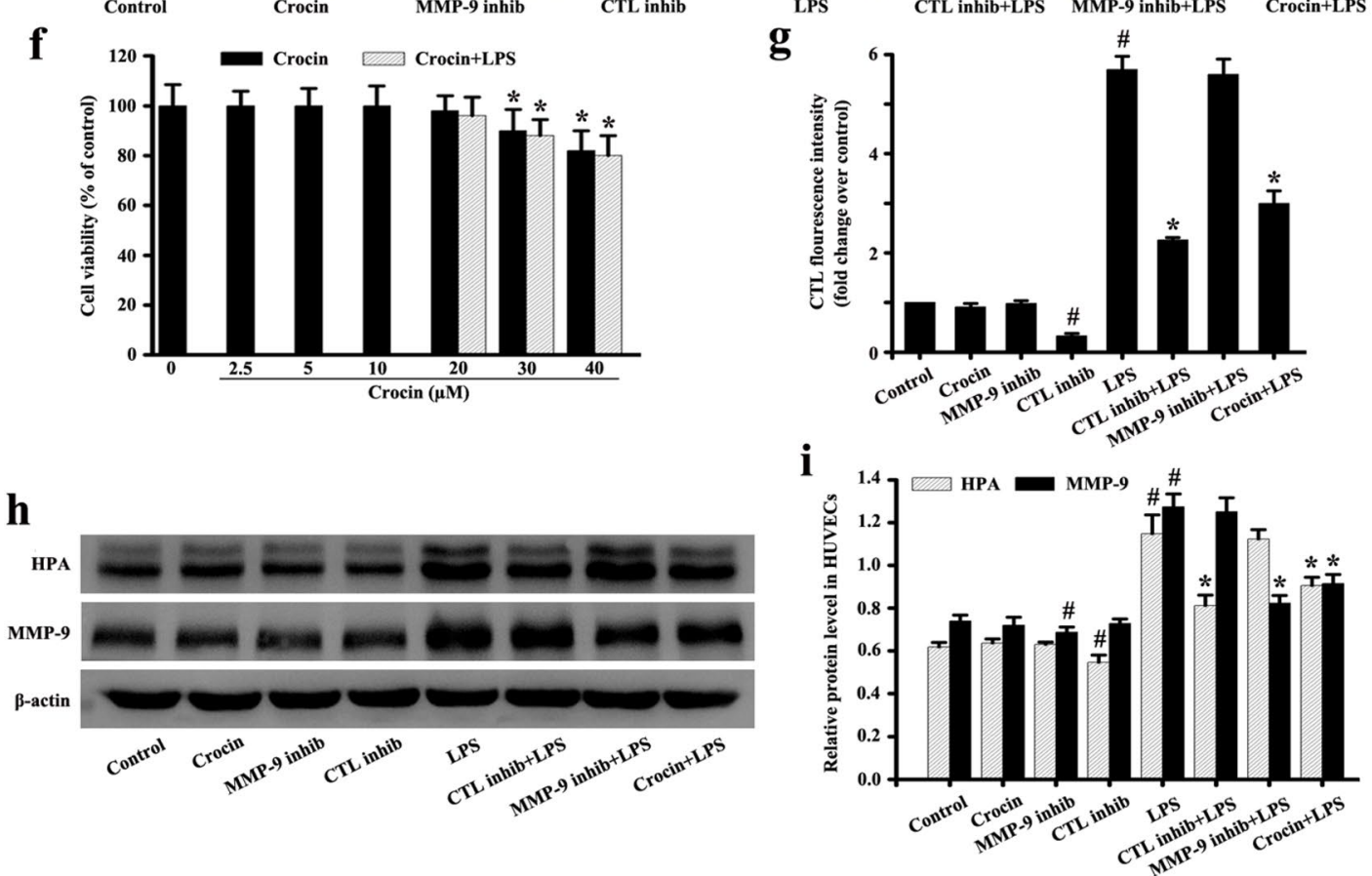
4Fig. 4 Effects of crocin on CTL and HPA, MMP-9 in LPS-induced ARDS mice and LPS-stimulated HUVECs. Following the process shown in Fig. 1a, the expression levels of CTL (a) and HPA, MMP-9 (c) in mice were detected (a, magnification $200 \times$, scale bar: $50 \mu \mathrm{m}$ ). d, b Protein intensity analysis of $\mathbf{c}$, a, respectively. The effect of crocin on cytotoxicity in HUVECs was determined by MTT assay (f). The expression levels of CTL (e) and HPA, MMP-9 (h) in HUVECs were detected (a, magnification $\times 200$, scale bar $50 \mu \mathrm{m})$. i, g Protein intensity analysis of $\mathbf{h}, \mathbf{e}$, respectively. All data are presented as means \pm SD of three independent experiments. ${ }^{*} p<0.05$ vs. control group, $* p<0.05$ vs. LPS group

Likewise, the results of cell experiments showed no significant changes in the crocin and control groups. However, LPS stimulation significantly increased IкB $\alpha$ phos-

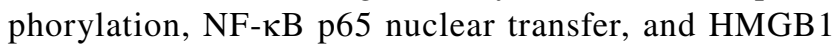
cytoplasmic transfer (Fig. 6b, d). Pretreatment with crocin
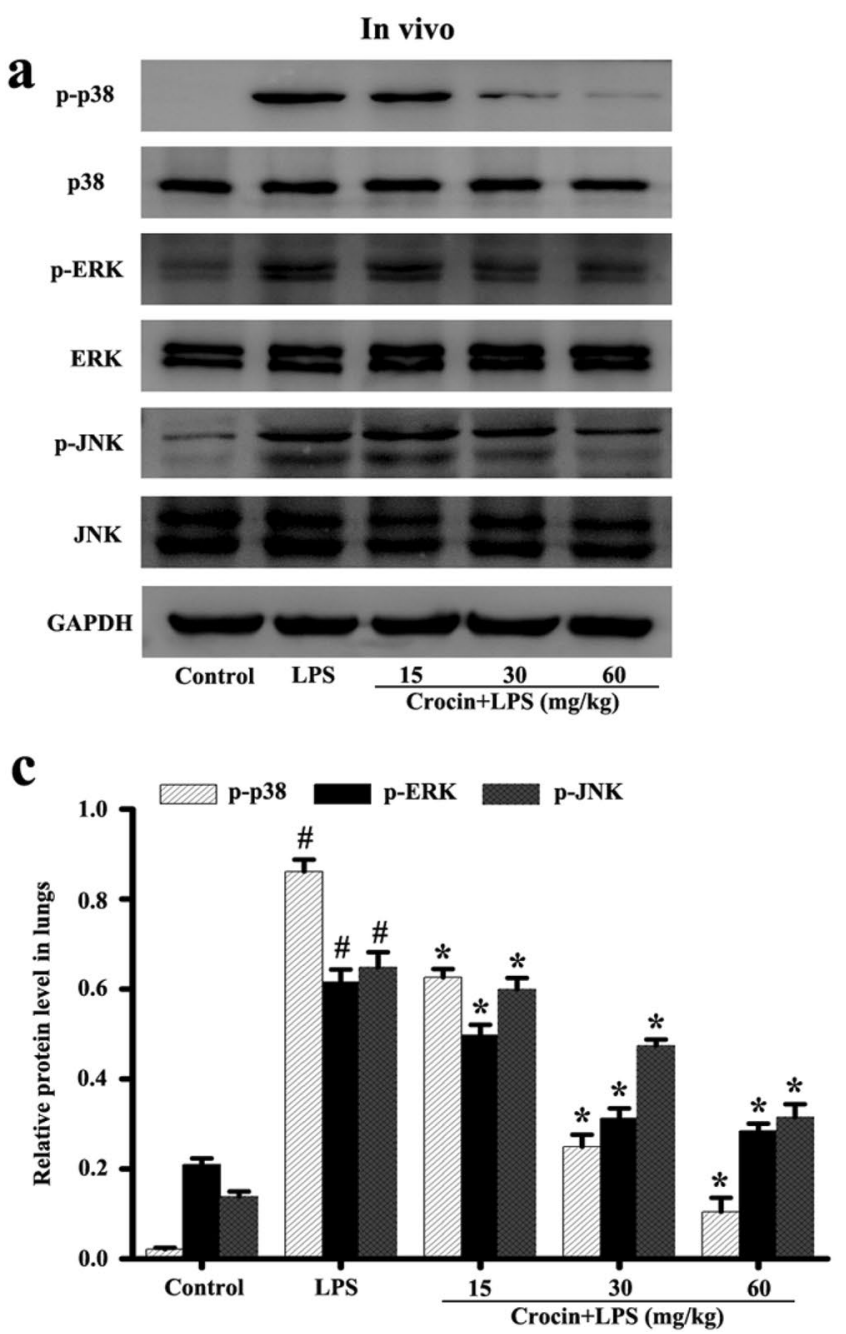

Fig. 5 Effects of crocin on MAPK pathway activation in LPS-induced ARDS mice and LPS-stimulated HUVECs. Following the process shown in Fig. 1a, the levels of phosphorylation and non-phosphorylation of p38, ERK, and JNK in lung tissues (a) and HUVECs (b) were significantly inhibited $\mathrm{I} \kappa \mathrm{B} \alpha$ phosphorylation, NF- $\mathrm{BB}$ p65 nuclear transfer, and HMGB1 cytoplasmic transfer (Fig. 6b, d).

These results suggested that crocin can inhibit the activation of the NF- $\mathrm{KB}$ and HMGB1 inflammatory pathway in LPS-induced ARDS mice and LPS-stimulated HUVECs.

\section{Discussion}

Increased vascular permeability is one of the important pathological features of ARDS. The pulmonary edema associated with albumin leakage is closely related to the endothelial glycocalyx degradation [8]. The endothelial glycocalyx acts not only as a physical barrier to prevent albumin exudation but also as an information molecule to

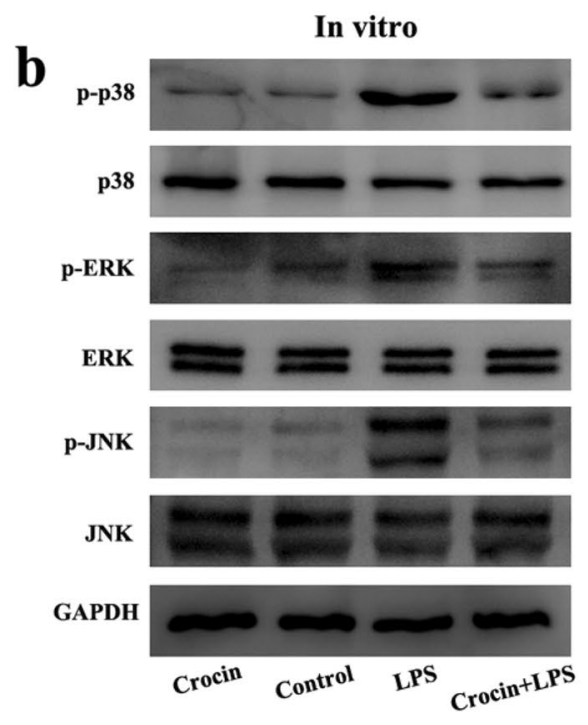

d

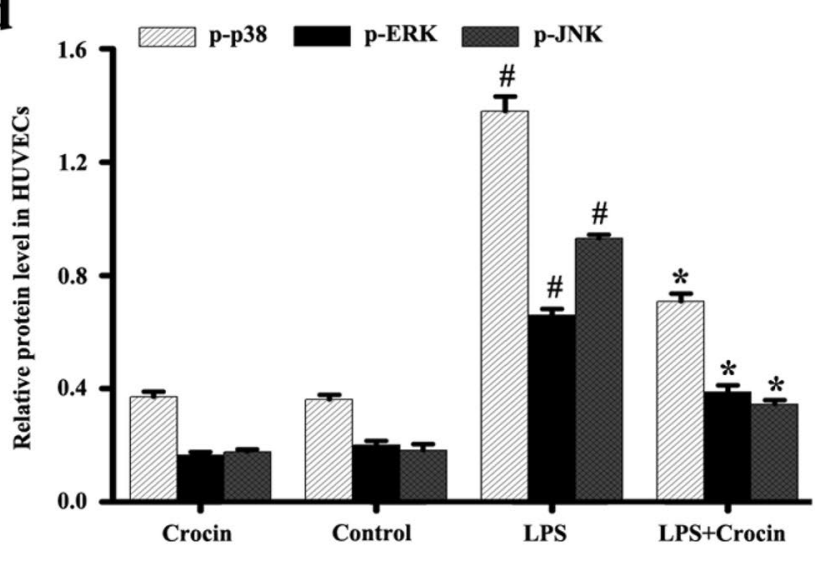

detected by Western blot. c, $\mathbf{d}$ Protein quantification of $\mathbf{a}, \mathbf{b}$, respectively. GAPDH was used as internal control. All data are presented as means \pm SD of three independent experiments. ${ }^{*} p<0.05$ vs. control group, $* p<0.05$ vs. LPS group 

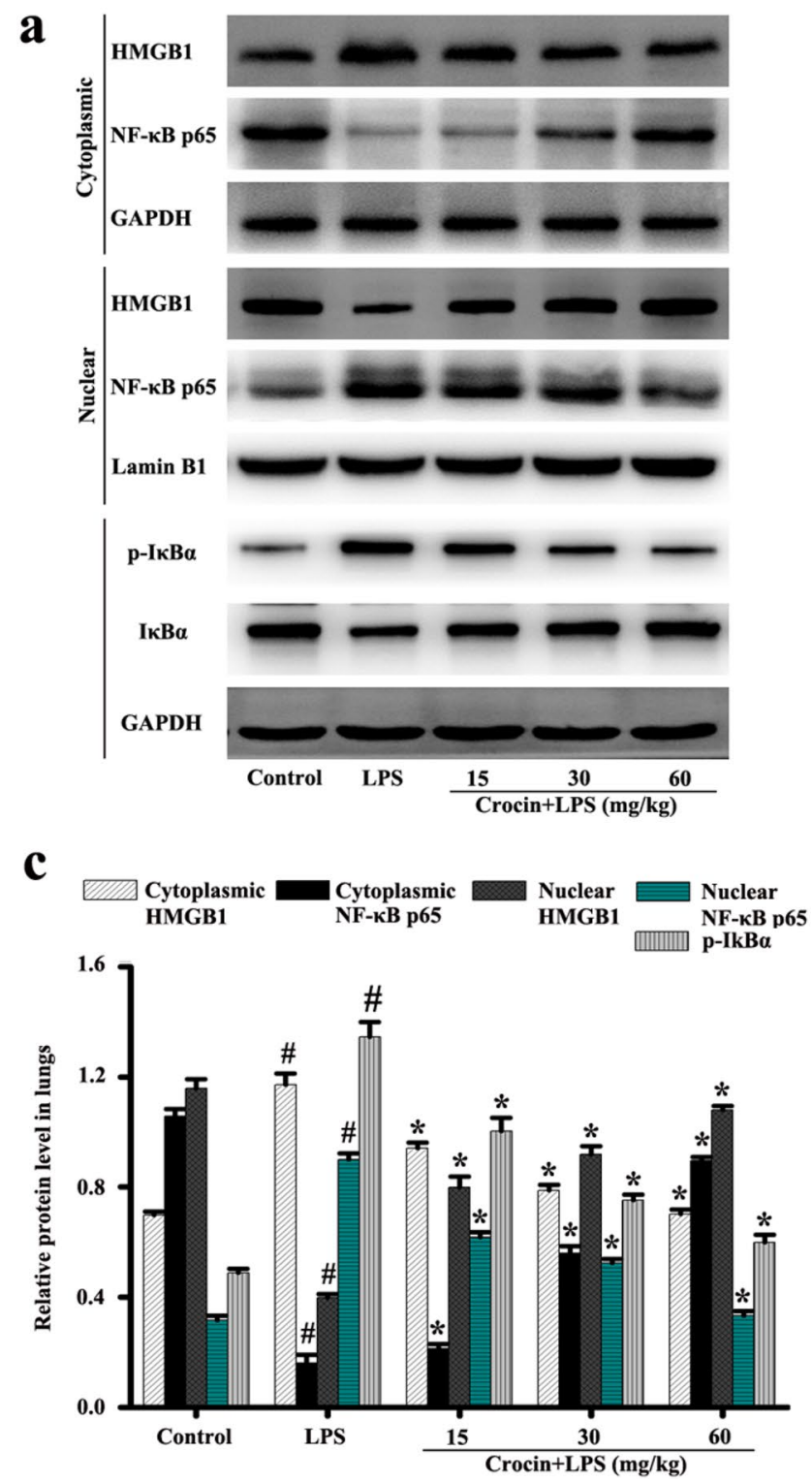

Fig. 6 Effects of crocin on HMGB1 and NF- $\kappa$ B pathway activation in LPS-induced ARDS mice and LPS-stimulated HUVECs. Following the process shown in Fig. 1a, the levels of HMGB1 and NF- $\mathrm{kB}$ p65 as well as the phosphorylation and non-phosphorylation of $\mathrm{I} \mathrm{B} \mathrm{B} \alpha$ in lung tissues (a) and HUVECs (b) were detected by Western blot. c,

participate in hemodynamics $[5-8,25]$. As shown in previous reports, crocin had an important protective effects in several diseases by affecting on cell apoptosis, arteriosclerosis, oxidation, and inflammation [15-19]. The present study demonstrated that pretreatment with crocin effectively improved the pulmonary edema associated with albumin leakage by maintaining the integrity of glycocalyx in LPS-induced ARDS mice. To our knowledge, this study is the first to reveal its protective effects and mechanisms of the endothelial glycocalyx.
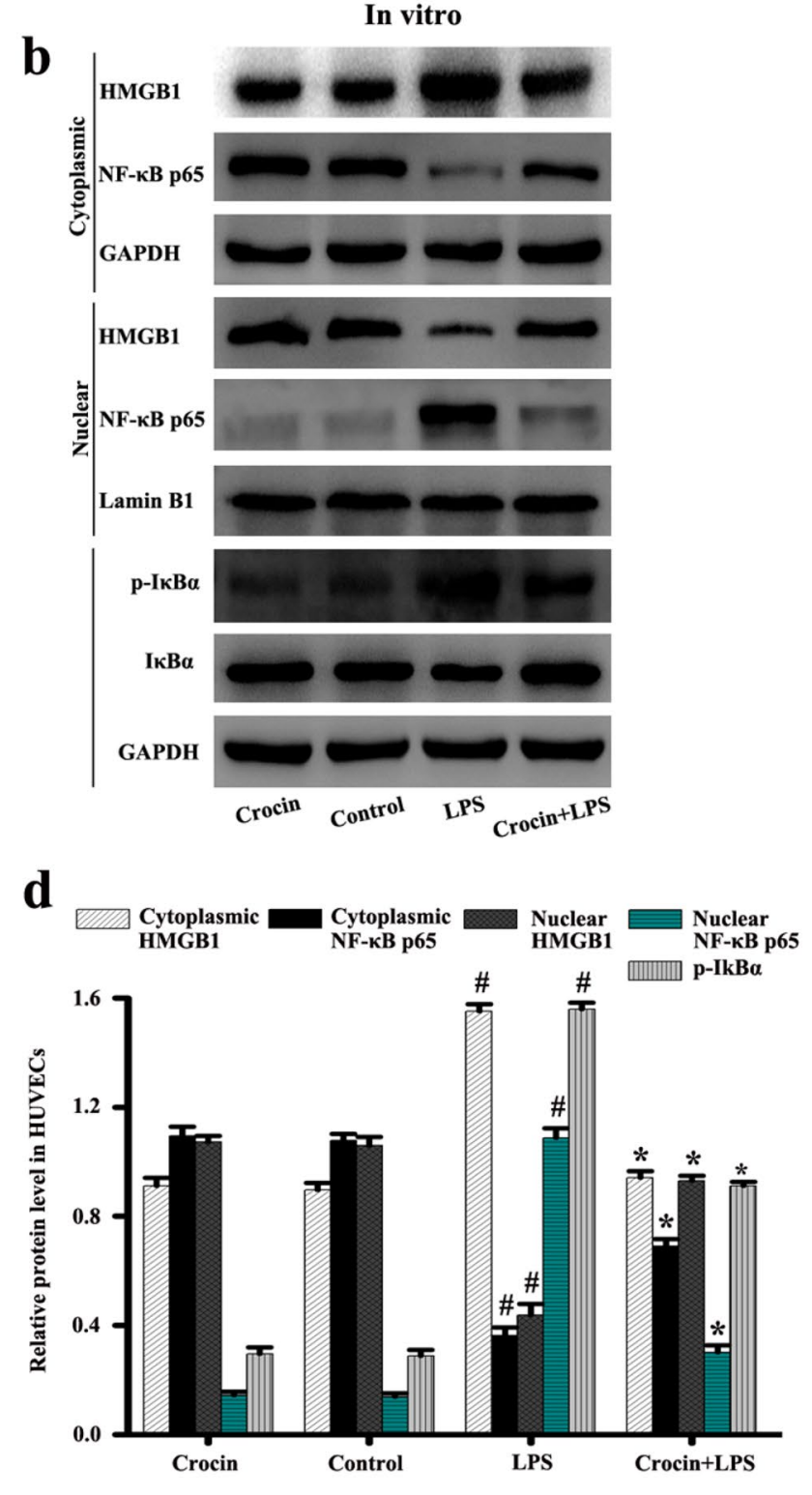

d Protein quantification of a, b, respectively. GAPDH or Lamin B1 was used as internal control. All data are presented as means \pm SD of three independent experiments. ${ }^{*} p<0.05$ vs. control group, ${ }^{*} p<0.05$ vs. LPS group

Enzymatic degradation had been found to be involved in the endothelial glycocalyx degradation. As shown in previous reports, MMP-9 can directly cause the shedding of SDC-1 in lung endothelial cells or SDC-4 in glomerular endothelial cells [10,26]. Additionally, Ramani et al. [27] found that the enzymatic hydrolysis of HS chain can promote SDC-1 shedding in the cell lines CAG, thereby indicating that non-MMP mechanism is also involved in the process of SDC-1 shedding. In the present study, cathepsin L inhibitor did not alleviate LPS-mediated SDC-4 
shedding, thereby suggesting that non-MMP mechanisms may not be involved in SDC-4 shedding. More importantly, the inhibition of MMP-9 expression by pretreatment with crocin is closely related to the reduction in SDC-4 shedding, and the inhibition of cathepsin L and HPA expression by pretreatment with crocin is closely related to the reduction in HS shedding.

$\mathrm{NF}-\mathrm{\kappa B}$ and MAPK are representative and important inflammatory pathways in the onset and development of ARDS pathogenesis, and they promote the production and secretion of inflammatory cytokines after activation [2, 28]. Otherwise, HMGB-1 as an important late inflammatory factor can trigger the intracellular NF- $\mathrm{KB}$ signaling pathway and aggravate serious injury [29]. As shown in previous reports, crocin had a strong anti-inflammatory effect in diabetic nephropathy model [18]. The results of this study also showed that crocin had the same strong anti-inflammatory effect in LPS-induced ARDS cell and animal models. However, inflammatory injury also induces the production and release of glycocalyx shedding factors (such as MMP-9 and HPA) [30, 31]. An incomplete glycocalyx may aggravate the inflammatory reaction and further spread inflammatory factors, resulting in persistent lung injury $[32,33]$. The present study showed that pretreatment with crocin effectively reduced glycocalyx damage, and this protective effect may be related to inhibiting the activation of inflammatory pathways.

During the ARDS process, activated neutrophils release intracellular toxic components so as to amplify the inflammatory response by recruiting more inflammatory cells into the site of damage [34]. Additionally, Ma et al. [35] reported that neutrophils were involved in regulating the microvascular endothelial permeability. Suzuki et al. [36] reported that neutrophil elastase damaged the pulmonary endothelial glycocalyx in LPS-induced endotoxemia. In the present study, pretreatment with crocin significantly improved the neutrophil adhesion or infiltration induced by LPS in ARDS mice. The ability of crocin to alleviate glycocalyx damage may be closely related to the reduction in neutrophil retention.

Oxidative damage is another important factor in the pathogenesis of ARDS. Oxidation/antioxidant imbalance can aggravate oxidative damage to tissues and cells [37]. Previous study reported that reactive oxygen species can damage the endothelial glycocalyx of the kidneys and lungs and modulate HPA expression of glomerular adriamycin nephropathy $[38,39]$. Additionally, crocin has been reported to improve methotrexin-induced liver injury by inhibiting oxidative stress in rats [40]. However, further studies are needed to determine whether crocin's protective effect on glycocalyx degradation of LPS-induced ARDS mice and LPS-stimulated HUVECs is also related to oxidative injury.
Interestingly, how to repair the damaged endothelial glycocalyx is another important topic in the study of endothelial glycocalyx $[3,41]$. The present study did not involve how the endothelial glycocalyx was repaired, and further studies are needed to determine whether crocin promotes the repair of the endothelial glycocalyx.

The full story is still incomplete. Given the limitations of laboratory conditions, the pharmacokinetic and hemodynamic changes in mice were not analyzed in the present study. The complete analysis of the pharmacokinetic and hemodynamic changes in mice will provide additional insights into crocin and endothelial glycocalyx.

Overall, the present study demonstrated that crocin can protect against HS and SDC-4 degradation by inhibiting enzyme expression. Enzyme inhibition may be related to the decrease in inflammatory responses or oxidative damage. These findings add new pharmacological functions to crocin, providing potential targets for new therapies to inhibit enzymes and potential pathways that lead to endothelial dysfunction and vascular leakage in ARDS, which may contribute to the treatment of this disease.

Acknowledgements This work was supported by funding from the National Natural Science Foundation of China (no.: 81670078).

\section{Compliance with ethical standards}

Conflict of interest The authors declare no conflict of interest.

\section{References}

1. Lin X, Barravecchia M, Kothari P, Young JL, Dean DA. $\beta 1-\mathrm{Na}(+)$, $\mathrm{K}(+)$-ATPase gene therapy upregulates tight junctions to rescue lipopolysaccharide-induced acute lung injury. Gene Ther. 2016;23(6):489-99.

2. Ma L, Zhao Y, Wang R, Chen T, Li W, Nan Y, et al. 3,5,4'-Tri$O$-acetylresveratrol attenuates lipopolysaccharide-induced acute respiratory distress syndrome via MAPK/SIRT1 pathway. Mediators Inflamm. 2015;2015:143074.

3. Yang Y, Haeger SM, Suflita MA, Zhang F, Dailey KL, Colbert $\mathrm{JF}$, et al. Fibroblast growth factor signaling mediates pulmonary endothelial glycocalyx reconstitution. Am J Respir Cell Mol Biol. 2017;56(6):727-37.

4. Strand ME, Aronsen JM, Braathen B, Sjaastad I, Kvaløy H, Tønnessen $\mathrm{T}$, et al. Shedding of syndecan-4 promotes immune cell recruitment and mitigates cardiac dysfunction after lipopolysaccharide challenge in mice. J Mol Cell Cardiol. 2015;88:133-44.

5. McDonald KK, Cooper S, Danielzak L, Leask RL. Glycocalyx degradation induces a proinflammatory phenotype and increased leukocyte adhesion in cultured endothelial cells under flow. PLoS ONE. 2016;11(12): 0167576.

6. Marki A, Esko JD, Pries AR, Ley K. Role of the endothelial surface layer in neutrophil recruitment. J Leukoc Biol. 2015;98(4):503-15.

7. Iba T, Levy JH, Hirota T, Hiki M, Sato K, Murakami T, et al. Protection of the endothelial glycocalyx by antithrombin in an endotoxin-induced rat model of sepsis. Thromb Res. 2018;171:1-6. 
8. Yang Y, Schmidt EP. The endothelial glycocalyx: an important regulator of the pulmonary vascular barrier. Tissue Barriers. 2013;1(1):23494.

9. Glasner DR, Ratnasiri K, Puerta-Guardo H, Espinosa DA, Beatty PR, Harris E. Dengue virus NS1 cytokine-independent vascular leak is dependent on endothelial glycocalyx components. PLoS Pathog. 2017;13(11):e1006673.

10. Reine TM, Lanzalaco F, Kristiansen O, Enget AR, Satchell S, Jenssen TG, et al. Matrix metalloproteinase- 9 mediated shedding of syndecan-4 in glomerular endothelial cells. Microcirculation. 2019;31:e12534.

11. Worthen GS, Schwab B, Elson EL, Downey GP. Mechanics of stimulated neutrophils: cell stiffening induces retention in capillaries. Science. 1989;245(4914):183-6.

12. Feng Z, Wang JW, Wang Y, Dong WW, Xu ZF. Propofol protects lung endothelial barrier function by suppression of high-mobility group box 1 (HMGB1) release and mitochondrial oxidative damage catalyzed by HMGB1. Med Sci Monit. 2019;25:3199-211.

13. Pace E, Ferraro M, Di Vincenzo S, Siena L, Gjomarkaj M. Effects of ceftaroline on the innate immune and on the inflammatory responses of bronchial epithelial cells exposed to cigarette smoke. Toxicol Lett. 2016;258:216-26.

14. Li L, Hu J, He T, Zhang Q, Yang X, Lan X, et al. P38/MAPK contributes to endothelial barrier dysfunction via MAP4 phosphorylation-dependent microtubule disassembly in inflammation-induced acute lung injury. Sci Rep. 2015;5:8895.

15. Xu GL, Qian ZY, Yu SQ, Gong ZN, Shen XC. Evidence of crocin against endothelial injury induced by hydrogen peroxide in vitro. J Asian Nat Prod Res. 2006;8(1-2):79-85.

16. Lee IA, Lee JH, Baek NI, Kim DH. Antihyperlipidemic effect of crocin isolated from the fructus of gardenia jasminoides and its metabolite crocetin. Biol Pharm Bull. 2005;28(11):2106-10.

17. Nie Z, Deng S, Zhang L, Chen S, Lu Q, Peng H. Crocin protects against dexamethasone-induced osteoblast apoptosis by inhibiting the ROS/ $/ \mathrm{Ca}^{2+}$-mediated mitochondrial pathway. Mol Med Rep. 2019;20(1):401-8

18. Li S, Liu X, Lei J, Yang J, Tian P, Gao Y. Crocin protects podocytes against oxidative stress and inflammation induced by high glucose through inhibition of NF- $\mathrm{BB}$. Cell Physiol Biochem. 2017;42(4):1481-92.

19. Dianat M, Radan M, Badavi M, Mard SA, Bayati V, Ahmadizadeh M. Crocin attenuates cigarette smoke-induced lung injury and cardiac dysfunction by anti-oxidative effects: the role of Nrf2 antioxidant system in preventing oxidative stress. Respir Res. 2018;19(1):58

20. Rajaei Z, Hadjzadeh MA, Nemati H, Hosseini M, Ahmadi $\mathrm{M}$, Shafiee S. Antihyperglycemic and antioxidant activity of crocin in streptozotocin-induced diabetic rats. J Med Food. 2013;16(3):206-10.

21. Wang L, Huang X, Kong G, Xu H, Li J, Hao D, et al. Ulinastatin attenuates pulmonary endothelial glycocalyx damage and inhibits endothelial heparanase activity in LPS-induced ARDS. Biochem Biophys Res Commun. 2016;478(2):669-75.

22. Aeffner F, Bolon B, Davis IC. Mouse models of acute respiratory distress syndrome: a review of analytical approaches, pathologic features, and common measurements. Toxicol Pathol. 2015;43(8):1074-92.

23. Li B, Lin Q, Hou Q, Yin C, Zhang L, Li Y. Alkannin attenuates lipopolysaccharide-induced lung injury in mice via Rho/ROCK/ NF-кB pathway. J Biochem Mol Toxicol. 2019;29:e22323.

24. Mammoto A, Mammoto T, Kanapathipillai M, Wing Yung C, Jiang E, Jiang A, et al. Control of lung vascular permeability and endotoxin-induced pulmonary oedema by changes in extracellular matrix mechanics. Nat Commun. 2013;4:1759.

25. Garsen M, Lenoir O, Rops AL, Dijkman HB, Willemsen B, van Kuppevelt $\mathrm{TH}$, et al. Endothelin-1 induces proteinuria by heparanase-mediated disruption of the glomerular glycocalyx. J Am Soc Nephrol. 2016;27(12):3545-51.

26. Lambaerts K, Wilcox-Adelman SA, Zimmermann P. The signaling mechanisms of syndecan heparan sulfate proteoglycans. Curr Opin Cell Biol. 2009;21(5):662-9.

27. Ramani VC, Pruett PS, Thompson CA, DeLucas LD, Sanderson RD. Heparan sulfate chains of syndecan-1 regulate ectodomain shedding. J Biol Chem. 2012;287(13):9952-61.

28. Bortolotto V, Grilli M. Every Cloud has a silver lining: proneurogenic effects of $A \beta$ oligomers and HMGB- 1 via activation of the RAGE-NF- $\mathrm{kB}$ axis. CNS Neurol Disord Drug Targets. 2017;16(10):1066-79.

29. Karuppagounder V, Arumugam S, Thandavarayan RA, Pitchaimani V, Sreedhar R, Afrin R, et al. Modulation of HMGB1 translocation and RAGE/NFKB cascade by quercetin treatment mitigates atopic dermatitis in NC/Nga transgenic mice. Exp Dermatol. 2015;24(6):418-23.

30. Kolářová $\mathrm{H}$, Ambrůzová $\mathrm{B}$, Šindlerová L, Klinke A, Kubala L. Modulation of endothelial glycocalyx structure under inflammatory conditions. Mediators Inflamm. 2014;2014:694312.

31. Schmidt EP, Yang Y, Janssen WJ, Gandjeva A, Perez MJ, Barthel $\mathrm{L}$, et al. The pulmonary endothelial glycocalyx regulates neutrophil adhesion and lung injury during experimental sepsis. Nat Med. 2012;18(8):1217-23.

32. Chelazzi C, Villa G, Mancinelli P, De Gaudio AR, Adembri C. Glycocalyx and sepsis-induced alterations in vascular permeability. Crit Care. 2015;19:26.

33. Johansson PI, Stensballe J, Rasmussen LS, Ostrowski SR. A high admission syndecan-1 level, a marker of endothelial glycocalyx degradation, is associated with inflammation, protein $\mathrm{C}$ depletion, fibrinolysis, and increased mortality in trauma patients. Ann Surg. 2011;254(2):194-200.

34. Santhosh MS, Sundaram MS, Sunitha K, Jnaneshwari S, Devaraja $\mathrm{S}$, Kemparaju K, et al. Propensity of crocin to offset vipera russelli venom induced oxidative stress mediated neutrophil apoptosis: a biochemical insight. Cytotechnology. 2016;68(1):73-85.

35. Ma Y, Yang X, Chatterjee V, Meegan JE, Beard RS Jr, Yuan SY. Role of neutrophil extracellular traps and vesicles in regulating vascular endothelial permeability. Front Immunol. 2019;10:1037.

36. Suzuki K, Okada H, Takemura G, Takada C, Kuroda A, Yano H, et al. Neutrophil elastase damages the pulmonary endothelial glycocalyx in lipopolysaccharide-induced experimental endotoxemia. Am J Pathol. 2019;189(8):1526-35.

37. Chen L, Li W, Qi D, Wang D. Lycium barbarum polysaccharide protects against LPS-induced ARDS by inhibiting apoptosis, oxidative stress, and inflammation in pulmonary endothelial cells. Free Radic Res. 2018;52(4):480-90.

38. Dull RO, Mecham I, McJames S. Heparan sulfates mediate pressure-induced increase in lung endothelial hydraulic conductivity via nitric oxide/reactive oxygen species. Am J Physiol Lung Cell Mol Physiol. 2007;292(6):L1452-L14581458.

39. Kramer A, van den Hoven M, Rops A, Wijnhoven T, van den Heuvel L, Lensen J, et al. Induction of glomerular heparanase expression in rats with adriamycin nephropathy is regulated by reactive oxygen species and the renin-angiotensin system. J Am Soc Nephrol. 2006;17(9):2513-20.

40. Kalantar M, Kalantari H, Goudarzi M, Khorsandi L, Bakhit S, Kalantar H. Crocin ameliorates methotrexate-induced liver injury via inhibition of oxidative stress and inflammation in rats. Pharmacol Rep. 2019;71(4):746-52.

41. Song JW, Zullo JA, Liveris D, Dragovich M, Zhang XF, Goligorsky MS. Therapeutic restoration of endothelial glycocalyx in sepsis. J Pharmacol Exp Ther. 2017;361(1):115-21.

Publisher's Note Springer Nature remains neutral with regard to jurisdictional claims in published maps and institutional affiliations. 